\title{
STUDY ON KNOWLEDGE AND PRACTICES OF THE USE OF BP 100 AMONG PARENTS OF CHILDREN WITH SEVERE ACUTE UNDER NUTRITION (SAU) AT TEACHING HOSPITAL KARAPITIYA
}

\author{
Kankananarchchi I. ${ }^{1 *}$, Fernando C.M.P. ${ }^{2 * *}$, Devasiri I.V. ${ }^{1}$, Dharmasiri H.H.K.T. ${ }^{1}$, \\ Jayathilaka E.A. ${ }^{1}$ and Shanika J.B.A.G. ${ }^{1}$ \\ ${ }^{1}$ Department of Paediatrics, Faculty of Medicine, University of Ruhuna, Sri Lanka \\ ${ }^{2}$ Department of Paediatrics, Faculty of Medicine, University of Kelaniya, Sri Lanka
}

\begin{abstract}
Severe acute under nutrition (SAU) is a major clinical problem among children under 5 years. In order to combat with it government of Sri Lanka introduced a commercial form of "ready to use therapeutic foods" known as BP 100. Objectives of the study were to assess the knowledge, attitudes and practices regarding the usage of BP 100 among parents of children aged 6 months to 59 months with SAU and study the palatability of the product. An Interviewer administered questionnaire was used to assess 50 caregivers of children with SAU receiving BP 100, attending to paediatric clinics at Teaching Hospital Karapitiya (THK). Of 50 children, 29 were boys. $82 \%(n=42)$ of the parents were unaware about the indication. Only $66 \%(n=33)$ considered it as a therapeutic food. Sharing of the product was observed in $8 \%(n=4) .16 \%(n=8)$ of parents had to discard some of the BP100 prescribed to their children. $42 \%(\mathrm{n}=21)$ of children liked to consume the product whereas $36 \%(n=18)$ had no special preference and $22 \%(n=11)$ refused to eat. The overall knowledge about the BP 100 was poor. Sharing was seen only in a minority. The palatability of BP 100 was good among children.
\end{abstract}

Keywords: Under nutrition, BP100, Knowledge, Attitudes, Practices, Parents

\section{Introduction}

Severe acute under nutrition is a major nutritional problem among children under 5 years. There are different classification systems to categorize under nutrition, out of which World Health Organization (WHO) recommendation is to use the weight for height or length. (WHO, 2013) SAU can be further divided in to SAU with complications and SAU without complications. Children with at least one of the following features are considered as having complications with SAU. Those are loss of appetite, lower respiratory tract infection, high fever, severe dehydration, hypothermia, pitting edema and extensive infection. (WHO, 2013) Clinically well, alert children and those who have good appetite, are categorized as SAU without complications. Children with complications need in patient management whereas others can be managed as an outpatient basis. (Ashworth, 2003)

In collaboration with UNICEF, ministry of health in Sri Lanka has launched a nutritional rehabilitation programme (NRP) in 2007. The commercial forms of ready to use therapeutic foods; BP 100 and Plumpy nut were introduced to the curative sector of the health under the NRP. (Ministry of Health, 2007)

BP 100 is a compressed energy dense food product specifically designed to use in the rehabilitation phase of the severe acute under nutrition. Wheat flour (baked), Oat flour (baked), Vegetable oil, Sugars, Milk proteins, 
Skimmed milk powder, Vegetable protein, Minerals, Amino acids and Vitamins are the ingredients of it. Calorie density of BP 100 is $540 \mathrm{Kcal} / 100 \mathrm{~g}$. (Product specifications sheet RUTF biscuit, 2017)

Thriposha was introduced to the country in early 1970 and it played a big role in the management of under nutrition in Sri Lanka. (Drake W.D. et al 1982) Though the majority of parents are aware about the usage of thriposha, the awareness about the use of ready to use therapeutic foods is doubtful. This has not been objectively assessed in the country.

Ten years have passed since the introduction of BP 100 and the evaluations of the effectiveness of the programme are under way. Though the number of children getting RUTF has gone up in the community the awareness about the use of the product has not improved proportionately.

\section{Objectives}

The objectives of the study were to study the knowledge regarding the usage, house hold practices of BP100 among parents of children with SAU, and the palatability of the product among children.

\section{Methods}

An observational descriptive study was carried out among parents of children with SAU who were on nutritional rehabilitation therapy with BP 100. The study was conducted during a period of four months from June 2017 to September 2017 in three paediatric clinics at Teaching Hospital Karapitiya, (THK) Galle, Sri Lanka. Approval for the study was obtained from the relevant authorities of the THK and Faculty of Medicine, University of Ruhuna. Parents of children with SAU who were on BP 100 at least for 4 weeks were taken as the inclusion criteria, whereas, parents of children who were on BP 100 of less than one-month duration and those who are not giving consent were excluded from the study. A total of 50 parents were taken part during the study period. All eligible parents who were attending to three paediatric clinics were enrolled in to the study with consecutive sampling.

A pretested interviewer administered questionnaire was used to collect the data. The questionnaire was pretested on 10 parents prior to administering to the study population. There were two main components in the questionnaire; basic socio dermographic variables and questions based to assess knowledge attitudes and practices of the product.

\section{Results}

Of 50 children, there were 29 males and 21 females. Male: Female ratio was 1; 0.7. Mother was the respondent in all 50 children. Seventy percent $(n=35)$ of mothers have educated up to Ordinary level. Sixteen percent $(n=8)$ and $10 \%(\mathrm{n}=5)$ of them have studied up to advanced level and up to primary education respectively.

Regarding the knowledge of the product, $82 \%(\mathrm{n}=42)$ of the parents were unaware about the correct indication of the therapy. Out of them 38 of mothers have believed low weight as the indication for BP100. Majority (92\%) of mothers were not aware about the recommended duration of the therapy and $24 \%(\mathrm{n}=11)$ of them believed it should be given until weight become normal. Only $66 \%(\mathrm{n}=33)$ considered it as a therapeutic food whereas, the rest $(n=17)$ have considered the product as a nutritional supplement. Only $60 \%(n=30)$ of mothers were aware about the ability of breast feeding during the therapy. The correct amount of water to be given with BP 100 was known only by $28 \%(\mathrm{n}=14)$. (Table 1 )

In $56 \%(\mathrm{n}=28)$ occasions mothers have given the biscuit twice a day and $12 \%(\mathrm{n}=6)$ and $6 \%(\mathrm{n}=3)$ have given it three times a day and frequent small feeds respectively. BP 100 was given mixing with other food items by $22 \%$ $(n=11)$. Sharing of the product was observed in $8 \%(n=4)$ and $16 \%(n=8)$ of mothers claimed that they had to 
discard some of the products prescribed to their children. Majority (94\%) of mothers have stored the product in a cool dry place. (Table 1)

With regards to the palatability of the product, $42 \%(\mathrm{n}=21)$ of children liked to consume it whereas, $36 \%$ $(\mathrm{n}=18)$ had no special preference and $22 \%(\mathrm{n}=11)$ refused to eat.

Table 1 Knowledge attitudes and practices about BP 100

\begin{tabular}{|c|c|}
\hline Question & Number/Percentage \\
\hline \multicolumn{2}{|c|}{ Do you know the reason behind starting BP 100 to your child? } \\
\hline Low weight & $38(76 \%)$ \\
\hline Low length & $01(2 \%)$ \\
\hline Low weight: length/ height & $09(18 \%)$ \\
\hline Not known & $02(4 \%)$ \\
\hline \multicolumn{2}{|c|}{ How long should you be giving this biscuit to your child? } \\
\hline 2 months & $05(10 \%)$ \\
\hline Until weight becomes normal & $11(22 \%)$ \\
\hline Not known & $34(68 \%)$ \\
\hline \multicolumn{2}{|c|}{ Do you consider this as a therapeutic food or nutritional supplement? } \\
\hline Therapeutic food & $33(66 \%)$ \\
\hline Nutritional supplement & $17(34 \%)$ \\
\hline \multicolumn{2}{|c|}{ According to your knowledge is it possible to breast feed the child during the period of giving BP $100 ?$} \\
\hline Yes & $30(60 \%)$ \\
\hline No & $08(16 \%)$ \\
\hline Don't know & $12(24 \%)$ \\
\hline \multicolumn{2}{|c|}{ How much of fluid should be given with 1 tablet of BP 100 biscuits? } \\
\hline $100 \mathrm{ml}$ & $14(28 \%)$ \\
\hline $200 \mathrm{ml}$ & $06(12 \%)$ \\
\hline Not known & $30(60 \%)$ \\
\hline \multicolumn{2}{|c|}{ How long can you keep it once you prepared it in to porridge form? } \\
\hline 3 hours & $04(8 \%)$ \\
\hline 24 hours & $00(00 \%)$ \\
\hline Not known & $46(92 \%)$ \\
\hline \multicolumn{2}{|c|}{ How frequently do you give BP100 to your child? } \\
\hline Once a day & $1(2 \%)$ \\
\hline Twice a day & $28(56 \%)$ \\
\hline Three times a day & $15(30 \%)$ \\
\hline Frequent small feeds & $06(12 \%)$ \\
\hline \multicolumn{2}{|c|}{ Do you give BP 100 after mixing with other food items? } \\
\hline Yes I often do & $1(2 \%)$ \\
\hline Yes sometimes I do & $10(20 \%)$ \\
\hline I never do & $39(78 \%)$ \\
\hline \multicolumn{2}{|c|}{ Do you share BP 100 with other members of the family? } \\
\hline Yes I often do & $1(2 \%)$ \\
\hline Yes sometimes I do & $3(6 \%)$ \\
\hline I never do & $46(92 \%)$ \\
\hline \multicolumn{2}{|c|}{ Do you have to discard some of the biscuits prescribed to your child? } \\
\hline
\end{tabular}




\begin{tabular}{|l|l|}
\hline Yes I often do & $2(4 \%)$ \\
Yes sometimes I do & $6(12 \%)$ \\
I never do & $42(84 \%)$ \\
\hline Where do you store these biscuits at home? & \multicolumn{2}{|l|}{} \\
\hline In a cool dry place & $47(94 \%)$ \\
In a refrigerator & $2(4 \%)$ \\
Not stored in a special place & $1(2 \%)$ \\
\hline Does your child like eating BP 100? & \\
\hline Yes & $21(42 \%)$ \\
No special interest & $18(36 \%)$ \\
No & $11(22 \%)$ \\
\hline
\end{tabular}

The overall knowledge about the BP 100 was poor. However, sharing was seen only in a minority. Moreover, the palatability of the product was good among children.

\section{Discussion}

This is the first study done in Sri Lanka to assess the Knowledge attitudes and household practices of a RUFT, BP100. Since it is being used in the management of under nutrition in the community setting, it is important to have the fullest support from parents of suffered children. Therefore, this information is important to improve the ongoing NRP.

The main indication of giving BP 100 is the low weight for length/ height. However, majority of parents believed that the low weight alone as the indication. This can create a false impression among parents of children with low weight for age with normal weight for length, that BP 100 as a product which is given to gain weight. Therefore, it is necessary to educate parents about the correct indication of the therapy.

According to the NRP, BP 100 should be given for 8 weeks duration with fortnightly weight monitoring. (Ministry of Health, 2007) This fact was not known by many mothers and it's important to make them aware about the exact duration of therapy in order to minimize unnecessary continuation of the therapy. Though BP 100 is used in the community setting, it is not a nutritional supplement like, Thriposha. However, majority (66\%) of parents were aware about this and still 1/3 of them weren't. Breast feeding during the period of giving BP 100 is allowed and majority $(60 \%)$ of them were aware bout this. Since BP 100 is a high calorie and electrolyte dense product, it is important to give it with adequate amount of water. The recommendation is to give $100 \mathrm{ml}$ of water with one tablet and only $28 \%$ of parents were aware about this. Moreover, once it make it in to porridge form it can be kept only for 3hours and the knowledge about this recommendation was poor. Therefore, it is necessary to emphasize parents on these practical aspects.

Thought there is no exact frequency of administering BP 100, majority of parents have given it twice (56\%) or thrice (30\%) a day . The idea behind giving the product is to take weight for length/height in to $-<2 \mathrm{SD}$ and then convert the individual in to Moderate Acute Under nutrition (MAU) level. Therefore, parents can administer the product at any time of the day even replacing major meals. Unlike Thriposha, BP 100 should not be given mixing with other food items due to interactions with micronutrient absorption. Out of all $78 \%$ of parents were aware about this. However, further education is needed to strengthen the practice. Sharing was a major drawback in Thriposha programme in the country. (Drake W.D. et al 1982) However, in this study, sharing of BP100 with others was $8 \%$. Wastage of the product was seen in $16 \%$ and measures should be taken to minimize it further. 
Palatability of the product was not assessed previously in the country even after ten years of commencing the programme. According to our survey only $22 \%$ of children with SAU refused to eat BP100 and $42 \%$ of parents claimed that their children are willing to eat it.

One limitation of the study was the small sample size. The study was initially planned with larger number, however, there was a shortage of BP 100 in the country during the study period.

Considering the results of the study, it is evident that parents need to be provided with more information about the NRP and the detailed instruction about the use of BP100 at household level. Furthermore, further researches should be carried out to determine the effectiveness of the product.

\section{Acknowledgements}

The authors would like to thank the parents of children who consented for the study and Nursing staff of three Paediatric clinics at Teaching Hospital Karapitiya, Galle, Sri Lanka.

\section{References}

World Health Organization: Updates on the management of severe acute malnutrition in infants and children. Geneva; 2013.

Ashworth, A., 2003. Guidelines for the inpatient treatment of severely malnourished children. World Health Organization.

Ministry of Healthcare and Nutrition Sri Lanka. Management of Severe Acute under nutrition: a Manual for Health Workers in Sri Lanka; 2007

Product specifications sheet RUTF biscuit (BP 100), date of access: 21/11/2017. https://www.unicef.org/supply/files/rutf_biscuit_bp-100_unicef_specs.pdf

Drake, W.D., Gunning, J., Horwitz, A., Miller, R.I., Rice, H.L. and Thenabadu, G., 1982. Nutrition programs in Sri Lanka using US food aid: an evaluation of PL480 Title II programs. Report prepared for US Agency for International Development, Washington, DC. 